\title{
HYDRANENCEPHALY (HYDRENCEPHALY)
}

\author{
BY \\ L. CROME and PETER E. SYLVESTER \\ From the Neuropathology Department, The Fountain Hospital, Tooting, London
}

(RECEIVED FOR PUBLICATION SEPTEMBER 30, 1957)

The terms 'anencéphalie hydrocephalique' and 'hydroanencéphalie' were first used by Cruveilhies $(1829,1862)$, although the condition appears to have been described even earlier by Breschet (Breschet, 1823, quoted by Kobelt, 1938). The designation was later abbreviated to 'hydranencephalie' ('Hydranenkephalie' in its original German spelling) by Kluge (1902) and Spielmeyer (1905). The subject has been reviewed by Lange-Cosack (1944) and, more recently, by Moser (1952), who collected 32 recorded cases. Many authors still refrain, however, from using the term, presenting similar cases as 'hydrocephalus', 'ox-bladder brain', 'Rindenblasen-porencephalie', 'hydro-microcephaly', 'porencephaly', 'schizencephaly', and so on. Some of the current textbooks do not even mention 'hydranencephaly', while, on the other hand, new cases are being reported (Watson, 1944; Hamby, Krauss and Beswick, 1950; Najman, 1953; Thelander, Shaw and Piel, 1953; Olive and Du Shane, 1953; Hallervorden and Meyer, 1956).

In this condition the cerebral hemispheres are replaced by thin-walled sacs containing cerebrospinal fluid. Its extreme form is incompatible with prolonged survival, and most of the reported cases have been either stillborn or children dying in early infancy. One of the two cases presented by LangeCosack, living to 1 year, was allegedly the oldest on record.

While few of these young infants are likely to come under the care of mental deficiency authorities, some, with 'partial hydranencephaly', if such a term be permitted, may live longer and be seen more frequently with low-grade mental defect. We feel justified, therefore, in reporting the following case of hydranencephaly which occurred in a consecutive series of 300 autopsies performed chiefly on lowgrade mentally defective children at the Fountain Hospital. If not extreme, the condition may be difficult or impossible to differentiate from related encephalopathies, particularly from hydrocephalus, and this is illustrated by a brief presentation of two further cases, showing some features of hydranencephaly.
Case 1. The patient, the first-born child of healthy parents aged 25 and 24 with no family history of mental or neurological illness, was delivered normally after a pregnancy lasting eight months. He weighed $2 \cdot 8 \mathrm{~kg}$. at birth and was apparently normal. He developed a cold on the third day and it was noticed then that he never slept more than a few hours at a time.

Constant screaming and the fact that the patient 'took no notice' by the time he was 3 months old caused the parents to seek advice. His head circumference was then $33 \mathrm{~cm}$. with the fontanelle slightly bulging even when not crying. The muscle tone in the limbs, but not in the neck and back, seemed good. The eyes tended to deviate downwards and to the right and the pupils reacted sluggishly to light. Fundal examination, difficult in the circumstances, revealed scattered discrete pigmentation. The left disc was pale and there was a large pale patch near the right disc. He failed to pass any of the usual milestones of development-sitting, crawling, standing, talking or gaining sphincter control. The head gradually increased, never exceeding, however, the limits of normal $-42 \mathrm{~cm}$. at 2 years.

Home care became increasingly difficult and he was admitted to the Fountain Hospital at 2 years 9 months, when he was assessed as an idiot with a mental age of 1 month. He weighed $11.4 \mathrm{~kg}$. and lay supine and helpless in his cot. The anterior fontanelle was patent but the skull was normal in shape and size. He could move his limbs and often bit his hands till they bled. Muscle tone was increased in the legs; the knee and ankle jerks were present and both plantar responses were extensor. The abdominal reflexes were absent. He was apparently blind and had marked nystagmus. Both pupils were semi-dilated and reacted sluggishly to light. Ophthalmoscopy confirmed the previous findings of retinal scarring with multifocal pigmentation. His hearing was doubtful. Cardiovascular, respiratory, alimentary and genito-urinary systems were normal.

Routine laboratory investigations such as the W.R., Mantoux and toxoplasmin skin tests were negative. (No other serological tests for toxoplasmosis were done.) Radiological examination at 3 years 9 months showed osteoporosis of the sella turcica and non-united cranial sutures. Later he was found to have a congenital dislocation of the left hip.

During his 18 months' stay in hospital he had several episodes of respiratory infection, vomiting and diarrhoea, and developed measles. He also suffered from petit mal 
attacks which gave way later to major fits, mostly diurnal, occurring two to four times a month for the last ten months of his life. He made no mental or physical improvement and died of bronchopneumonia at $4 \frac{1}{2}$ years.

\section{Pathological Findings}

Necropsy. The subject was an extremely dehydrated and emaciated boy weighing $8.9 \mathrm{~kg}$., with regular features and a profuse growth of fine hair over the face and trunk. The head measured $50.5 \mathrm{~cm}$. in circumference. A naevus was present on the left calf, but there were no other external deformities. The trachea and bronchi contained thick secretion and the lungs showed hypostatic congestion, and focal consolidation with 'geographical' surface markings. A few petechiae were present on the pleural surface. All other organs, excepting the brain and eyes, appeared normal.

Microscopical examination of the lungs revealed a combination of lobular collapse with partial infective atelectasis, and inhalation pneumonia. Some alveoli adjoining the areas of collapse were filled with amorphous debris, others contained phagocytic cells of varying size. These had small, darkly-staining nuclei and irregularly outlined, sometimes enormously distended, vacuolated and reticulated cytoplasm. Plasma-cell infiltration was present round the margins of some of the areas of collapse and inhalation pneumonia.

\section{Central Nervous System}

The cerebral hemispheres were incised on opening the skull and it was therefore impossible to ascertain whether any of the considerable amount of fluid was subdural. The brain(Fig. 1), emptied of cerebrospinal fluid, weighed $210 \mathrm{~g}$. The left cerebral hemisphere $(13 \cdot 5 \times 9 \times 5 \cdot 2 \mathrm{~cm}$.) was represented over the greater part by a paper-thin, transparent sac, marked on its surface by attenuated blood-vessels. Only the posterior and basal portions of the occipital and temporal lobes were more solid, measuring up to $0.4 \mathrm{~cm}$. in thickness. The right hemisphere was better preserved. Its medial surface was also paper-thin, but the rest averaged $0.8 \mathrm{~cm}$. in thickness. While the thinnest parts of the hemispheres were smooth, more solid areas presented a characteristic microgyric pattern, varying from flat 'moroccoleather' to coarser 'cobble-stone' markings. Where it could be measured, the ratio of grey to white matter was about 2 to 1 . The internal surface of the hemispheres was smooth and glistening, showing, however, many irregularly distributed nodular elevations of up to $0.2 \mathrm{~cm}$. in diameter. The distended ventricles communicated by a circular central opening (Fig. 2), $4.3 \mathrm{~cm}$. in diameter, the anterior margin of which was formed by the thin fornices. The corpus callosum could not be identified. The basal ganglia were recognizable, the caudate nucleus

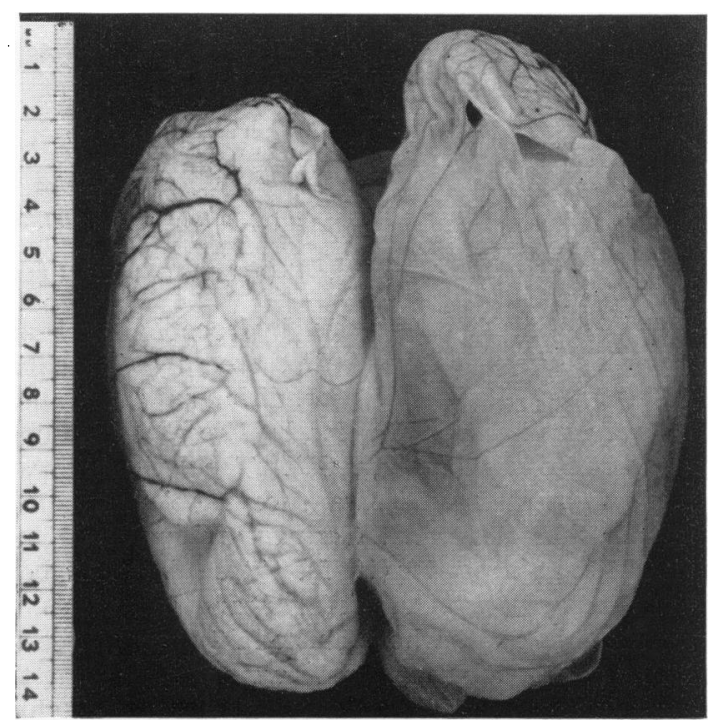

FIG. 1.-Case 1: dorsal view of brain with attenuated vessels on the surface of a dilated and diaphanous left ventricle which has been distended with a balloon.

being relatively large. A thin, elongated connexus thalamicus was stretched across the greatly dilated third ventricle.

The cerebellum, flattened from above downwards, was

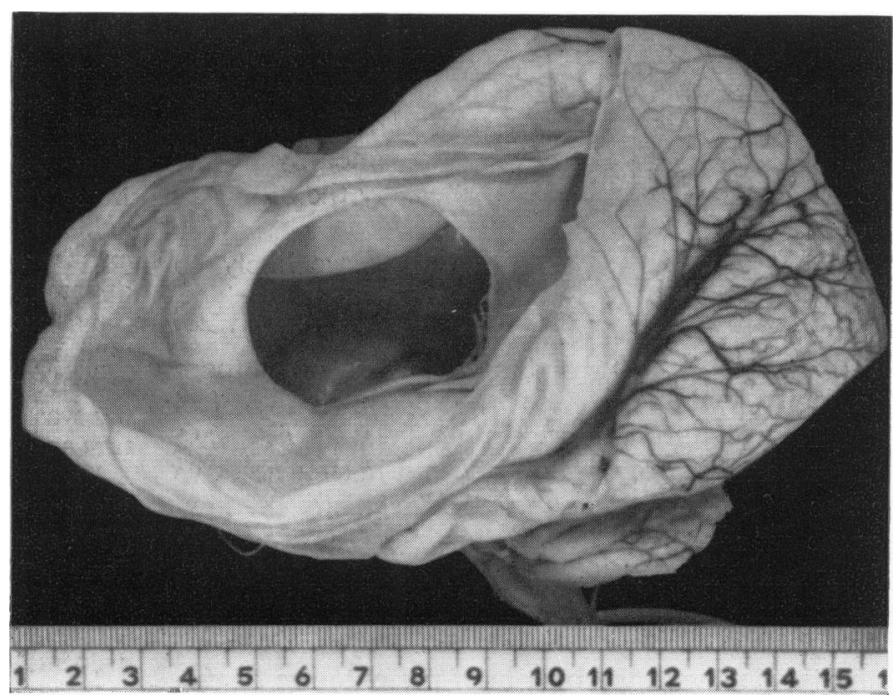

Fig. 2.-Case 1: a large foramen of Monro and dilated lateral ventricles revealed through an incision in the left cerebral cortex. 
small, weighing with the brain-stem $42 \cdot 0 \mathrm{~g}$. The pattern of the arbor vitae was blurred and many folia were narrow. In the brain-stem, the aqueduct of Sylvius was minute and the pyramids absent. The blood-vessels, cranial nerves (with the exception of the optic nerves) and the spinal cord appeared to be normal.

The Eyes. The eyes (Fig. 3), equal in size, measured $2 \cdot 2 \mathrm{~cm}$. in diameter. Both showed pronounced, cupped macular scarring with pigmentation in and around the scars. Each of the macular scars was larger than the disc, showing 'grease-spot' translucency when held to the light. Scattered pigmentation and smaller scars were also present elsewhere, being more marked in the temporal halves of the globes. The cornea, anterior chambers, irides, ciliary bodies and sclerae seemed normal. The optic nerves were small.

\section{Microscopy}

After prolonged fixation in formalin, representative blocks of the cerebral hemispheres, basal ganglia, brainstem, cerebellum and spinal cord were embedded in celloidin and in paraffin. Sections were stained by the usual neurological and general histological methods. Frozen material was also used as required.

The meninges were essentially normal. Arteries were thin-walled in the subarachnoid space over the hydranencephalic areas, and slightly thickened over the more solid parts of the brain. The external part of the cortical molecular layer was densely gliosed and showed capillary proliferation in some of the better preserved parts (Fig. 4), the glial cells and fibres tending towards parallel orientation to the surface. In places, the glial tissue projected ridgewise into the subarachnoid space.

The cytoarchitectonic structure of thicker portions of the cortex may be summarized as follows. It was most normal in the hippocampus where the molecular and pyramidal-cell layers, the alveus and fascia dentata were clearly identifiable. The arrangement elsewhere was greatly disturbed, bearing no relation to normal lamination. Some areas showed

Fig. 3.-Case 1: macular scarring and scattered pigmentation $\times 3$.
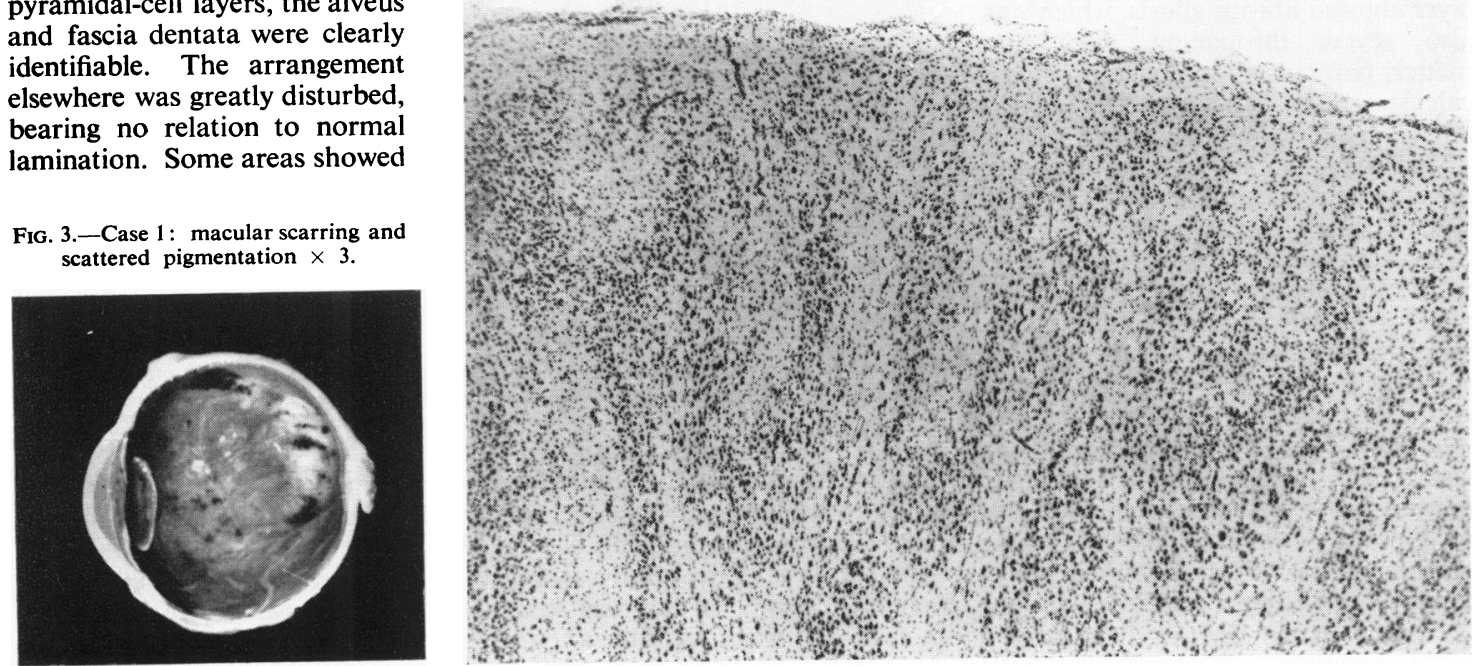

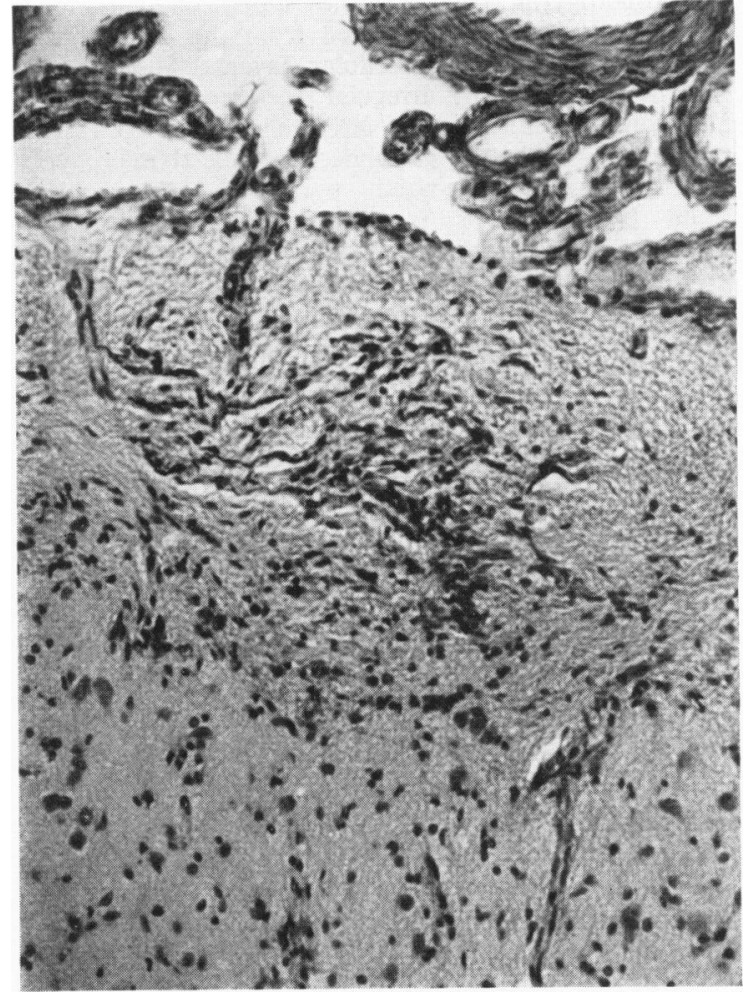

FIG 4-Case 1: the external molecular layer of the cortex with glial fibres arranged parallel to the surface. Haematoxylin and $\operatorname{cosin} \times 200$.

FIG. 5.-Case 1: cortical microgyria. Haematoxylin and eosin $\times 30$. 
true microgyria (Fig. 5), the superficial garlanded neuronal layer being separated from the deeper grey matter by a sparsely cellular layer. The pattern elsewhere was greatly irregular, defying identification and concise description. Nerve cells varied from area to area: some, in the garlanded superficial microgyric layer were medium-sized pyramids, others were small pyramidal or pleomorphic. Nissl substance stained poorly or not at all. Small delicate bundles of myelinated nerve fibres projected from the main mass of the white matter into the central areas of the microgyric convolutions where these were identifiable. Many irregularly orientated ectopic nerve cells were present in the white matter, forming in its deeper portions small clusters or larger islets, and, particularly near the ventricles, a continuous layer (Fig. 6). These heterotopic

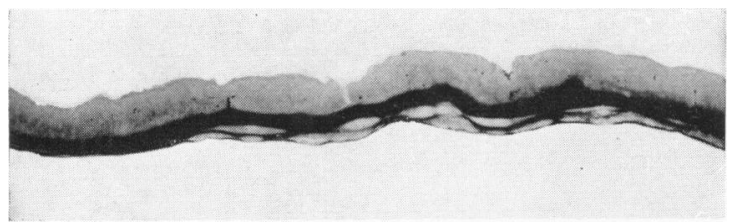

Fig. 6.-Case 1: ectopic grey matter. Heidenhain $\times 5$.

formations of grey matter accounted for the nodular naked-eye appearance of the internal surface of the cerebral hemispheres. Here many of the heterotopic nerve cells showed shrinkage with pyknosis of nuclei and accentuation of dentritic staining. The white matter contained also, near or at the ventricles, many islets and layers of glial cells interspersed densely with particles of calcium (Fig. 7). The latter were mainly extracellular, varying greatly in size. The smallest were dustlike, about $1 \mu$ in size, while the largest measured up to 20 to $30 \mu$.

Most of the ventricular lining, entirely devoid of ependyma, was formed by 12 to 15 rows of glial cells and fibres. In appropriately stained sections this layer showed fibrous gliosis, which was also severe throughout the white matter, particularly in and around the calcified foci, and, as mentioned already, in the sub-pial cortical layer.

The only neutral fat seen was in a few compound granular corpuscles situated in the perivascular spaces, and in some endothelial capillary cells.

The membrane (Fig. 8) enclosing most of the left and a large part of the right hemispheres was formed by partially fused soft meninges externally and $a$ thin uniform layer of glial tissue internally. No stratification of this glial layer could be discerned in thin sections but a certain pattern was visible in appropriately stained thicker sections of celloidin-embedded material. Here the most superficial layer contained few cells and this was followed by a more cellular glial zone, containing also occasional larger degenerate-looking nerve cells and a

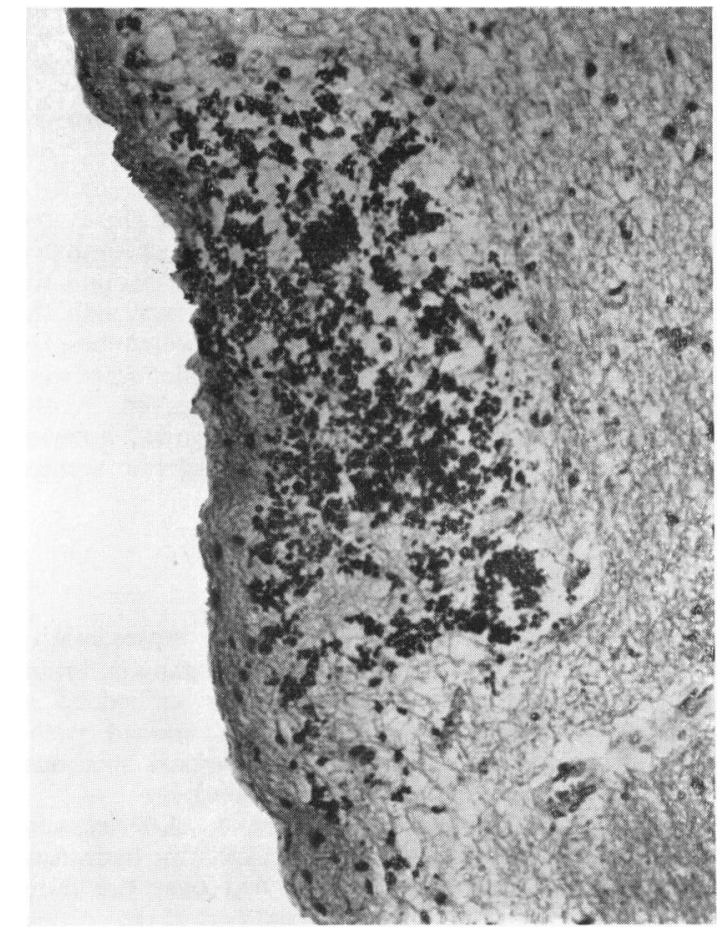

FIG. 7.-Case 1: periventricular calcification. Haematoxylin and eosin $\times 200$.

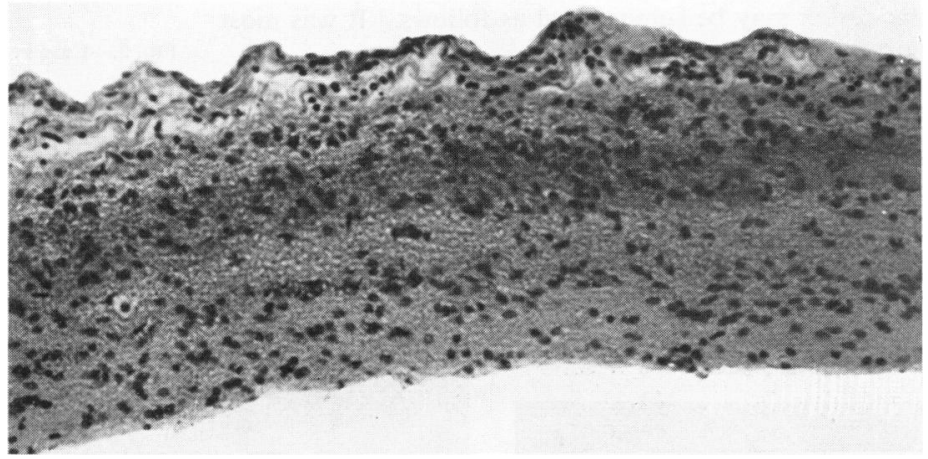

FIG. 8.-Case 1: the cortical membrane composed of partially fused meninges with gliosed cortex. Neurones and ependyma are absent. Haematoxylin and eosin $\times 200$.

few compound granular corpuscles. Scanty fragmented and ballooned myelin fibres coursed tangentially in the subjoining layer, which was succeeded internally by irregularly arranged glial cells and fibres. The internal surface was straight and even, showing in a few places foci of linear condensation of four to $\mathbf{1 0}$ glial cells. 
The basal ganglia were compressed against the base of the skull and the upper part of the striate bodies displaced laterally, presenting, however, little histological abnormality. Normal ependyma lined the entire ventricular system below a point corresponding to the middle of the thalamus. A few ependymal granulations were present. The internal and external capsules were thin on the right side and barely visible on the left. Their myelin stained, however, better than the white matter of the cerebral hemispheres.

Almost the entire cerebellum was microgyric (Fig. 9). by a loose meshwork of fibres containing a few glial cells, with, perhaps, some granules of pigment in the choroid. Moderate degeneration was more extensive, and some normal structural components were usually recognizable in these areas. The retina here was reduced in width, ganglion cells scarce and one or both the nuclear layers depleted of cells. The degree of pigmentation varied greatly, but there was no direct relation between atrophy and pigmentation, some of the most severely degenerated areas showing little or no pigment. The pigment, where present, was mostly extracellular being situated mainly in the external retinal and internal choroid layers, often filling completely elongated spaces. Smaller collections of pigment could also be seen occasionally in the more internal retinal layers. No inflammatory reaction or organisms were present in any of the numerous sections examined.

The neural funiculi of the optic nerves were narrow, and the pial septa thickened.

FIG. 10.-Case 1: retinal atrophy and pigmentation. Haematoxylin and eosin
$\times 200$.

Straight or slightly curved tapering streaks of granular and Purkinje cells budded and branched near the surface from stouter and more normally formed folia. Owing to tangential cutting, layers of Purkinje cells were often multiple. The white matter of the cerebellum showed diffuse fibrous gliosis, particularly heavy close to the fourth ventricle, but the dentate and roof nuclei seemed well preserved.

The cerebral peduncles, cortico-pontine fibres and medullary pyramids were rudimentary. The nuclear formations of the brain-stem seemed well developed. A diffuse, fine fibrous gliosis was present throughout the brain-stem, which was most marked around the ventricular and external surfaces. The aqueduct was elongated antero-posteriorly and split into an anterior smaller and posterior larger channel by a bridge of glial tissue in its narrowest portion. Here the widest diameter measured $0.27 \mathrm{~mm}$. and the channel was surrounded by a dense ring of fibrous glia. The constricted portion of the aqueduct widened rapidly with the approach to the considerably dilated fourth ventricle.

The spinal cord showed also diffuse fibrous gliosis, the grey matter being particularly affected. The lateral columns were narrow but showed no discrete areas of demyelination.

Eyes. The retinae and choroid showed widespread focal atrophy varying in extent and severity. Areas of extreme degeneration (Fig. 10) were represented merely

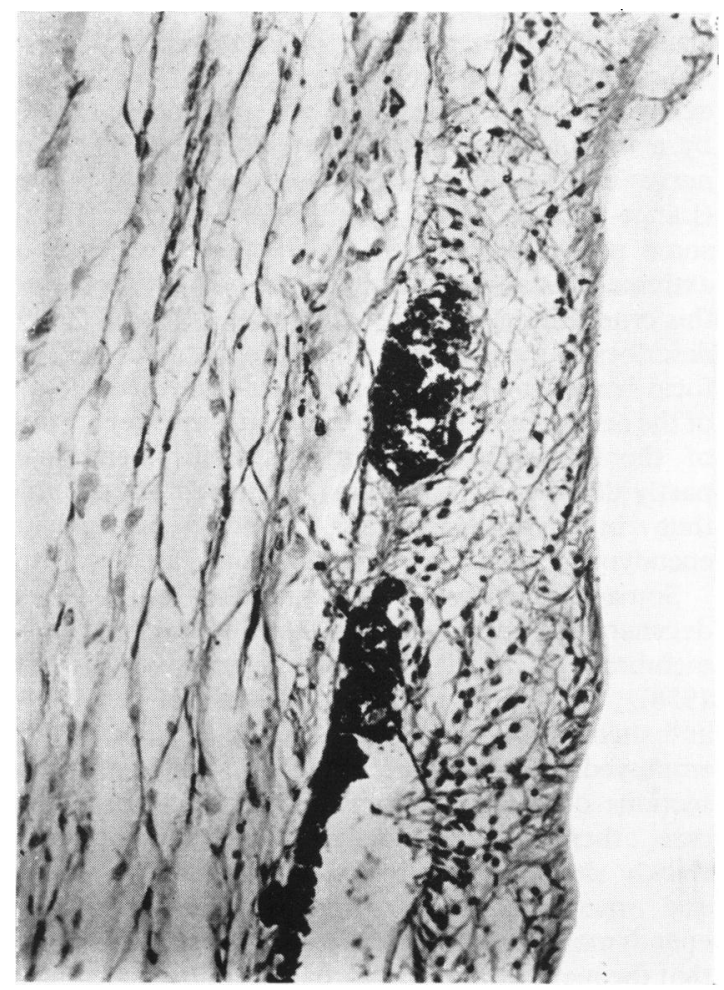




\section{Discussion}

Morphology. The size of the hydranencephalic cerebral hemispheres has been inconstant in recorded cases. Some, particularly of older patients, have been large, others normal or frankly micrencephalic. The cardinal feature is absence of all or the greater part of solid cerebral tissue. Where any remains, it is usually found in the basal aspects of the occipital and temporal lobes. This was explained by LangeCosack by the greater participation of the vertebral, as contrasted with the carotid arteries, in the supply of these areas. The basal ganglia and the rostral parts of the mid-brain are also absent or degenerate in the most severe cases. Formations below this level are usually substantially intact, showing merely agenesis of the long descending tracts. An exception was cystic change in the cerebellum in a case published by Thelander et al. (1953).

The meninges, hydranencephalic membrane and remaining brain tissue are often frankly haemorrhagic, reddish or brownish in colour, showing haemosiderin pigment histologically. Proliferation of phagocytic and meningeal cells, and the presence of fibrin, leucocytes and glial cells have also been noted in some cases.

The histological structure of the membrane enclosing the cystic hemispheres is regarded as crucial in differentiating hydranencephaly from hydrocephalus. In hydranencephaly it is formed externally by the arachnoid and pia and internally by a thin layer of glial tissue said to be devoid of nerve cells, axis cylinders or ependymal lining (Lange-Cosack, 1944; Peters, 1951; Moser, 1952), some neural parenchyma being preserved even in extreme instances of hydrocephalus. However, this criterion may not be conclusive. Russell (1949) describes a membrane in hydrocephalus caused by focal herniation of the ventricular wall through one of the deeper cerebral outer sulci with wide separation of the bordering convolutions. This membrane, partly denuded of ependyma, appeared to resemble that in hydranencephaly, although strips of ependymal cells were present in that case.

Some of the earlier workers also found a few degenerated nerve cells in the hydranencephalic membrane (Kluge, 1902; Spielmeyer, 1905; Kobelt, 1938). Moreover, the demonstration of nerve cells and their processes depends partly on the methods employed. While none could be seen in the thin sections of the paraffin-embedded material in our case, other areas embedded in celloidin and cut more thickly showed unequivocal evidence of nerve cells and myelinated nerve fibres. The absence of ependymal lining is likewise regarded as evidence that the membrane is not formed as in hydrocephalus by the peripherally displaced ventricular wall. This, again, may not be unequivocal. The ependymal lining is, as mentioned already, often partially shed in cases of hydrocephalus, and the ventricular wall can be identified in its absence by the characteristically stratified arrangement of glial cells and fibres in such areas. This was clearly present over a large part of the internal surface of the membrane in our case. A condition, similar to human hydranencephaly was, moreover, described in newborn and stillborn calves by Whittem (1957). He found that the membrane in these cases was formed externally by meninges and internally by ependyma, the intervening spaces containing ragged fragments of well-preserved cortical tissue with nerve cells, astrocytes and other elements. It seems, therefore, that although remnants of neural parenchyma are always scarce, they may not be entirely absent in the hydranencephalic membrane. This would depend, presumably, on the degree and duration of the condition.

The fluid in the hydranencephalic hemispheres is usually clear cerebrospinal fluid. It may, however, be turbid or blood-stained, especially in early cases and after ventricular or spinal puncture.

Stenosis around the foramina of Monro was present in one of Lange-Cosack's cases, and atresia of the Sylvian aqueduct in a case described by Watson. In another instance (Hurowitz, 1936), whose classification is uncertain (vide infra), there was no communication between the cerebral cysts and the anterior part of the aqueduct, which was split into many narrow channels. Many of the recorded cases have not been fully examined but some block in the cerebrospinal fluid pathway, functional or anatomical, is frequent; thus Beswick (1948) and Hamby and his colleagues (1950) failed to recover in the cerebrospinal fluid obtained by lumbar puncture dye injected earlier into cerebral ventricles in most cases where this procedure was tried. Aqueductal stenosis was present in our case, the lumen being approximately a quarter of the narrowest width of the normal $(0 \cdot 1 \mathrm{~cm}$.) reported by Sutton (1950), but it is uncertain whether this was the sole cause of the accumulation of the fluid above it.

As expected from the relatively long survival, our case showed more preservation of cerebral tissue especially on the right side, than in other recorded instances. It presented, in addition, microgyria, periventricular calcification and chorioretinopathy with pigmentation, the aetiological significance of which will be discussed below. Similar retinal changes were present in two of the hitherto reported cases (Hamby et al., 1950; Beswick, 1948). 'Micro- 
gyria' was mentioned by Kluge in his case, but it is impossible to decide from his description whether this was true microgyria, as in ours.

Aetiology, Pathogenesis and Classification. It seems generally agreed that hydranencephaly results from destruction and resorption of preformed solid cerebral tissue commencing before birth. The possible pathogenetic mechanisms have been fully discussed by Lange-Cosack (1944) and Becker (1949), both favouring ischaemia as the mechanism of the condition and Lange-Cosack suggesting further that this follows compression of the foetal carotid arteries by the umbilical cord or amniotic adhesions. Becker was able to produce comparable unilateral changes in newborn puppies by the injection of a mixture of paraffin and olive oil at a melting point of $40^{\circ} \mathrm{C}$. into one of the carotid arteries. The ensuing changes were, successively, necrosis, resorption, and, after nine months to one year, smooth-walled cavitation enclosed by a 'hydranencephalic' membrane. He thought that compression of the carotids might lead first to thrombosis, all intra-arterial traces of which would disappear in time. A case of unilateral cystic degeneration associated with recanalized thrombosis of the middle cerebral artery was reported by Meyer (1949). While this may well be the explanation in some cases, it is difficult to reconcile with the lack of mention of arterial thrombosis in any other of the recorded cases. Moreover, cerebral arteries of hydranencephalic infants observed at craniotomy or by means of angiography by Hamby and by Thelander and their colleagues were patent and, apparently, normal. It is certainly difficult to relate the distribution of the changes in our case to any known arterial pattern.

Congenital syphilis was present in two of the 17 cases reviewed by Lange-Cosack. In an infant aged 20 days presented by Kluge, hydranencephaly was associated with meningo-encephalitis of obscure aetiology. Hallervorden and Meyer noted severe maternal trauma during pregnancy in four of the recorded instances, mentioning focal meningeal inflammatory exudate in their own case. The morphological features of our case, 'hydrocephalus', cerebral calcification and macular scarring with pigmentation, also suggest infection, i.e., toxoplasmosis. Although this could not be confirmed, the diagnosis need not be ruled out by the negative skin test (Sabin and Feldman, 1949) or the absence of identifiable organisms in the no-longer active lesions examined at autopsy. The presence of true microgyria indicates a disturbance occurring before the sixth month of gestation (Crome, 1956).
It seems unlikely that the aetiology and pathogenesis of hydranencephaly are identical in all cases. Thus, very similar changes may set in even postnatally, as in the case described by Kopp (1912) where an entire cerebral hemisphere was converted into a hydranencephalic cyst following severe head injury at the age of 3 years. In a case reported by Globus (1921) as porencephaly, but having certain features of hydranencephaly, there was some histological evidence of inflammation and the author suggested that the condition had been caused by an encephalitis originating in intra-uterine life. It has also been suggested that such changes may result from birth injury (Schwartz, 1927), but this opinion was challenged by later workers on the grounds that the condition is often fully developed in newborn and stillborn infants, and that in some other cases, the patients are, unlike cases of birth injury, relatively symptom-free in the immediate post-natal period.

Typical hydranencephaly can be distinguished from the many variants of cystic encephalopathy, in which cavities are smaller and usually multiple, and from porencephaly in which narrow clefts or funnel-shaped defects traverse all or most of the cortex and white matter. However, there is no unanimity in the use of these terms and less typical forms of hydranencephaly are likely to be classified into one of the above groups.

The relation of hydranencephaly to hydrocephalus presents some difficulty. On account of the frequent evidence of preceding cerebral destruction and resorption, hydranencephaly is regarded as an extensive variant of encephaloclastic porencephaly, quite distinct from hydrocephalus, by most of the recent authors (Lange-Cosack, 1944; Peters, 1951; Moser, 1952). On the other hand, raised intracranial pressure, cranial enlargement, and functional obstruction of the cerebrospinal fluid have been frequently observed in hydranencephaly. These have been interpreted as evidence of hydrocephalus developing secondarily as a complication of hydranencephaly.

The problem depends partly on definition. The term 'internal hydrocephalus' usually refers comprehensively to any excessive accumulation of fluid in the ventricular system. The causes are diverse and include obstruction of the cerebrospinal fluid pathway, oversecretion of fluid or failure of its absorption (Russell, 1949). In other cases hydrocephalus may be a part of a complex of developmental abnormalities. It is likely, for example, that parts of the cerebral vesicles which fail to develop offer less resistance to transient rise in intraventricular pressure than the less abnormal ones, and that localized ventricular dilatation, so frequent in cases. 
of cerebral malformation, may arise in this manner. Ventricles may also dilate passively (hydrocephalus 'ex vacuo') following atrophy, scarring or resorption of the overlying tissue. If severe and extensive, such destruction may result in hydranencephaly.

Thus, viewed in the light of current definitions, the distinction between hydranencephaly and hydrocephalus would seem to be one of degree, particularly since some of the morphological criteria on which it is largely based have, as stated already, certain limitations.

It may be argued, however, that cases with primary atrophy and destruction of the ventricular wall and periventricular tissue ('encephaloclastic hydrocephalus') should not be included in the general group of hydrocephalus. If so, considerable difficulty will often be encountered in distinguishing between primary and secondary atrophy. The reason for the frequency of raised intra-cranial pressure and of signs associated with it (vide infra) in hydranencephaly also remains to be elucidated, although some periventricular and aqueductal stenosis was demonstrated in a few of these cases.

Moreover, some of the less typical variants of hydrocephalus which are common among mental defectives may present certain hydranencephalic features as illustrated by the following two cases.

Case 2. This girl, the younger of two siblings with a family tree free from mental or nervous illness, was born after a normal pregnancy and labour. She failed to develop mentally and was admitted to the Fountain Hospital at 6 months of age. At that time she was characteristically microcephalic with a head circumference of $27 \mathrm{~cm}$. The fontanelles and sutures were closed and the skull showed ridging over the sagittal and lambdoid sutures. The scalp was loose and transversely folded. The only other external abnormalities were two raised vascular naevi, one over the scapula and the other upon the back of the left hand. She had grand mal attacks, screamed frequently and failed completely to develop mentally. Routine laboratory tests were negative. During her stay in hospital she had several attacks of respiratory infection, succumbing to one following measles at 16 months.

Necropsy findings, confirmed microscopically, were bronchiolitis, focal collapse and infective atelectasis, and pulmonary oedema.

The brain (Fig. 11), looking like a periwig, was even smaller (116 g. with cerebrospinal fluid) than would be expected from the smallness of the skull $(34 \mathrm{~cm}$.) and there was much fluid in the subdural space. The cerebral hemispheres (Fig. 12) above a horizontal plane corresponding approximately to the middle temporal gyri were converted to fluid-filled sacs enclosed by a paper-thin membrane. Con- spicuous, somewhat tortuous vessels, coursed over the membrane, the lower half of which was rough on its external surface. The internal lining of the membrane was smooth and glistening. The transition from the upper membranous to the lower solid part of the brain was clear-cut. The latter (Fig. 12) showed microgyria above, and a smooth surface with broad gyri and short, shallow sulci upon its inferior and basal aspects. The anterior commissure was present, the foramina of Monro dilated, the fornices thin and the

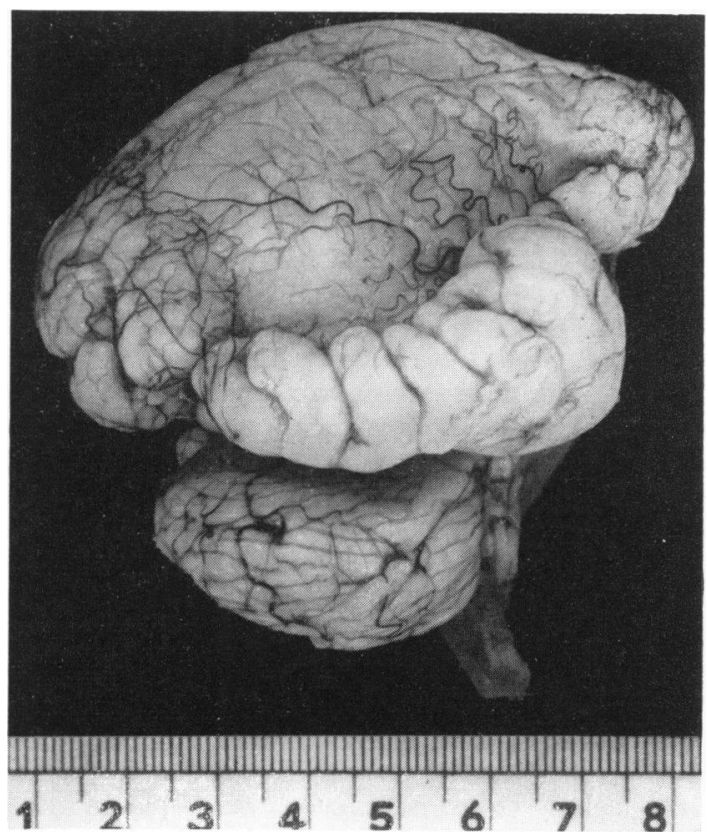

Fig. 11.-Case 2: lateral view of brain with 'periwig' appearance. 
corpus callosum rudimentary. The choroid plexuses in the lateral ventricles were large. The third and fourth ventricles, with the aqueduct, were dilated. The cerebellum, together with the brain-stem, weighed $42 \mathrm{~g}$. The pyramids were absent, and the inferior olives prominent. The optic and oculomotor nerves were thin. Other cranial nerves and basal blood-vessels seemed normal.

The histological appearances were similar to those in Case 1. The thin membrane was formed by soft meninges and a layer of glial tissue mostly devoid of ependyma. The arachnoid was, however, unlike Case 1, irregularly thickened, fibrosed and deficient in places. There was excessive collagenization and proliferation of blood vessels penetrating the glial layer from the meninges. No recognizable nerve cells or myelin fibres were present in the membrane, which showed focally dense fibrous gliosis and many accumulations of glial cells. Considerable neuronal loss and fibrous gliosis were present in the basal ganglia. Some of the cerebellar folia were thin and poorly cellular, but showed no definite microgyria.

COMment. While this case presented obvious hydranencephalic features, there were also significant differences. No history of raised intracranial pressure was suggested clinically or by the morphological findings. In particular the intraventricular pathway was patent. The sharp transition from the inferior solid to the membranous upper part of the brain was striking, and the picture as a whole dominated by pronounced micrencephaly. The findings can be best interpreted as hydrocephalus following uneven pallial agenesis, complicated later by meningeal fibrosis and widespread cerebral gliosis. Morphologically, the condition can be best classified as hydrocephalus with severe micrencephaly.

Case 3. This boy, the first child of a 24-year-old healthy unmarried mother, was born at term by Caesarean section performed for an abnormal lie. The birth weight was $4 \mathrm{~kg}$. Normal milestones were not attained. At 4 months, he began to show signs of hydrocephalus, the head circumference being $46 \mathrm{~cm}$. at 6 months. He was admitted to the Fountain Hospital when 16 months old as a hydrocephalic idiot with spastic quadriplegia and bilateral optic atrophy. The head circumference at that time was $58 \mathrm{~cm}$. and this increased by $1.3 \mathrm{~cm}$. during the next five years. Routine laboratory tests were normal. He failed to advance, developing flexor contractures of the limbs, frequent respiratory infections, and eventually dying at 7 years 3 months of bronchopneumonia-confirmed at necropsy.

Translucent meninges covered an abnormally shaped brain (Figs. 13 and 14), weighing $850 \mathrm{~g}$., in which there was great thinning of the cortex in the occipital region (3-4 mm.) and temporal lobes $(0.5 \mathrm{~mm}$.). Below the inferior temporal sulci and extending on to the inferior surface of the lobes the gyral pattern was lost, being preserved elsewhere in the brain. The depth of sulci varied from area to area being greatest in the parietal regions, shallow over the thin temporal or occipital cortex. The sulci were wide and deep in the frontal areas. The cerebellum (with brain stem) weighed $126 \mathrm{~g}$., and showed, bilaterally, around the horizontal fissure

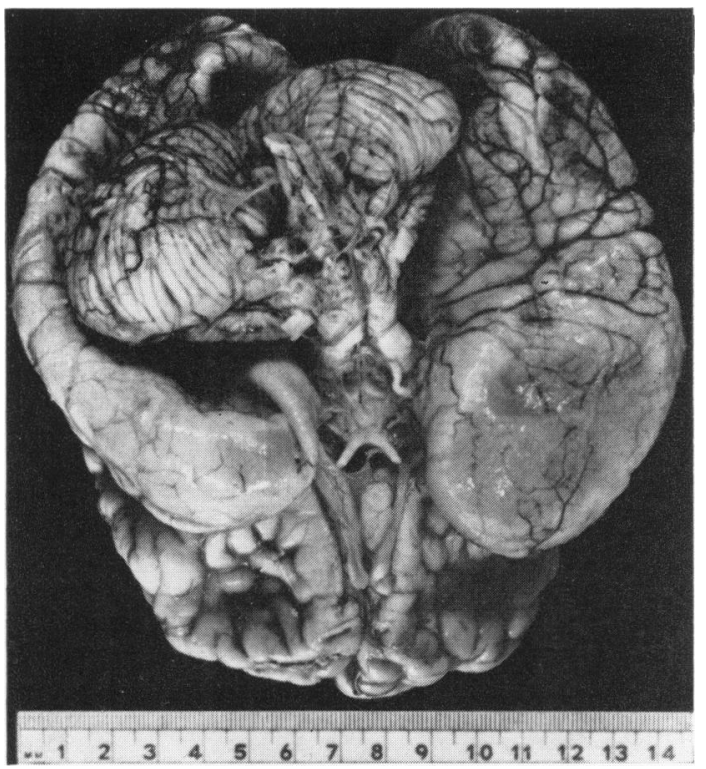

FIG. 13.-Case 3: ventral view of brain with thin temporal lobes.

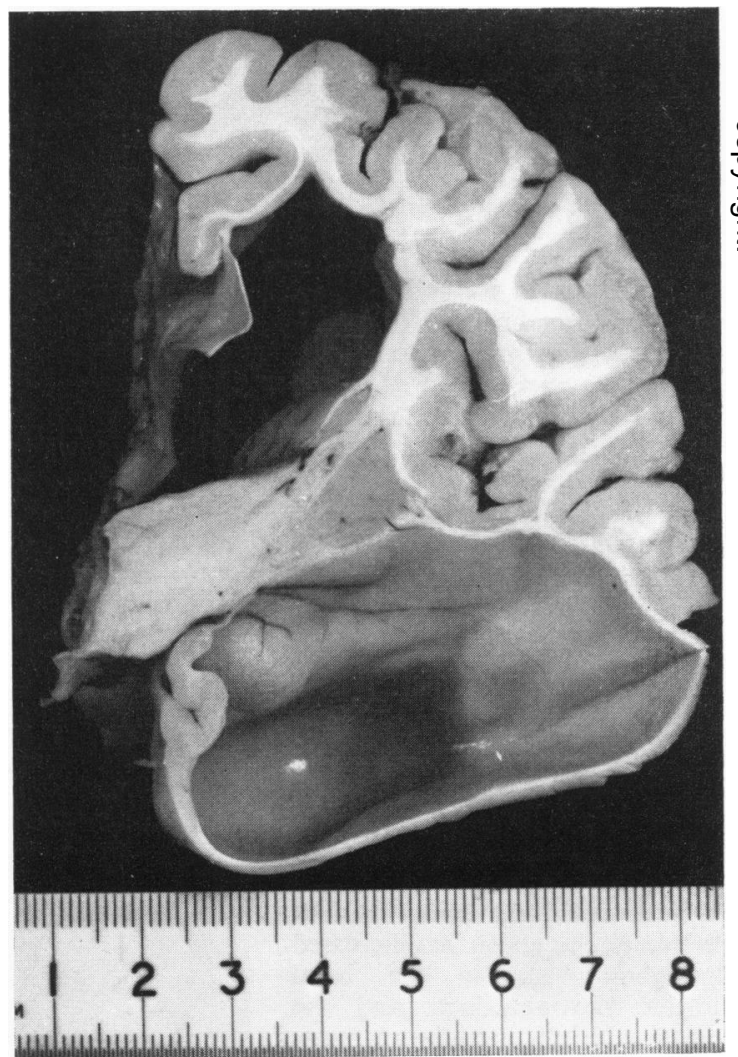

FIG. 14.-Case 3: extreme thinning of the right temporal lobe and dilatation of the lateral ventricle. The corpus callosum is thin. 
several atrophic and yellow discoloured folia. The ventricular system, including the aqueduct of Sylvius (Fig. 15) was greatly dilated. The ventricular lining was

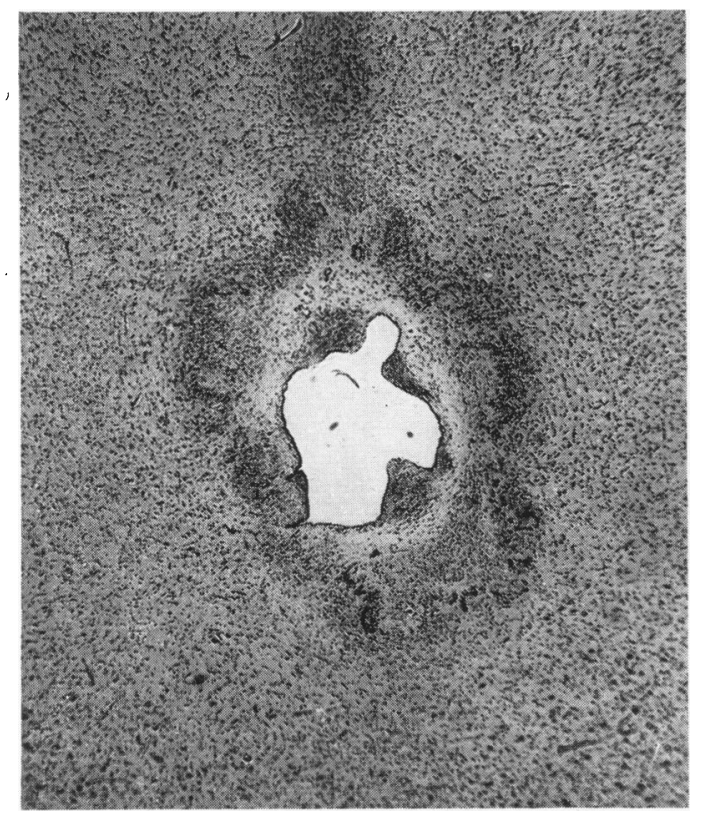

Fig. 15.-Case 3: ependymal granulations and increased gliosis of the aqueduct of Sylvius. Nissl $\times 25$.

smooth except in the fourth ventricle where it had an 'ox-tongue' roughness. The entire corpus callosum was thinned. The pyramids were small. Choroid plexuses and blood vessels appeared normal with the exception of those vessels over the thinned temporal lobes, which were reduced in number and calibre. The optic nerves were small and firm but other cranial nerves appeared normal.

Save for lesser stratification of glial cells and the presence of haemosiderin, the membrane (Fig. 16) representing the thinned temporal cortex was similar to the preceding cases. A few degenerated neurones, some of which were calcified, were present in it. In other areas, laminar structure was preserved even in the thinned occipital cortex. Haemosiderin was present in the cerebellum and adjacent meninges, being most marked in the atrophic folia which showed also loss of Purkinje cells and demyelination. Periventricular gliosis was increased throughout, and in the basal ganglia, the aqueduct, and the fourth ventricle, there were many coarse ependymal granulations. The cortico-spinal tracts were small.
CoMment. Unlike Case 1, the intraventricular pathway in this instance appeared sufficiently patent. Pronounced ependymal granulations suggest past infection, and haemosiderin deposits indicate old haemorrhage. Either or both these factors may have played a significant part in the pathogenesis.

Unlike Cases 1 and 2, there was no evidence of an embryological defect such as microgyria or micrencephaly.

This case is not an uncommon example of communicating hydrocephalus, but the structure of the membrane fulfils the morphological criteria of hydranencephaly (Lange-Cosack).

Despite all the unresolved difficulties, it seems useful to retain a special descriptive term for cases with unequivocal features of hydranencephaly, though this is not, perhaps, the happiest designation. Cruveilhier employed it to describe what he believed to be a combination of anencephaly and hydrocephalus, but this is not really the case. Anencephaly is now known to be a distinct and obvious malformation in which the calvarium is not formed and the brain is represented by a disordered hamartomatous arrangement of vascular and immature neural tissue, often described as 'area cerebrovasculosa'. Although a transitional case showing certain features of both hydranencephaly and anencephaly has been described by Hurowitz, it remains unique and seems different from all other instances of hydranencephaly, in which the skull is complete and the brain is not hamartomatous.

It seems preferable, therefore, to avoid the suggestion of anencephaly in the designation, and 'hydrencephaly' is, perhaps, a better term.

\section{Clinical Features}

It appears from a perusal of the literature that a few cases of hydranencephaly show cranial enlargement at or soon after birth, and occasional neonatal

FIG. 16.-Case 3: the thin gliosed membrane of the temporal cortex with normal meninges. Haematoxylin and eosin $\times 50$. 
jaundice has also been recorded. Usually, however, the newborn is normal in appearance and behaviour for the first days or weeks. Feeding difficulty, frequent screaming and hypothermia are common later, and these are followed by incoordinate eye movements, strabismus and nystagmus. The optic discs are pale; light reflexes may be present or absent. Movements of limbs are usually present and tendon jerks are brisk. In a few weeks or months the head begins to enlarge, intracranial pressure rises and signs of hyper-irritability develop. A 'cracked-pot' sound is often elicited. The pressure of the cerebrospinal fluid is raised and the fluid often shows excess of protein. Spasticity becomes apparent, and many forms of convulsion and tremor occur. The patients are sometimes anaemic. Failure of mental development is increasingly obvious. Transillumination of the skull is a useful and safe diagnostic procedure (Strasburger, 1910; von Bókay, 1923), a reddish reflection being often seen not only over the skull, but through the retinae and ears. The electroencephalogram may be quite flat and the ventriculographic appearances are diagnostic.

Lange-Cosack distinguished two groups of hydranencephaly. Patients in the first, with the greater loss of cerebral tissue and involvement of subcortical centres, are severely disabled and show disturbance of autonomic regulation. They do not survive beyond the first month. The subcortical centres are not involved in the second group, and patients deteriorate less rapidly. It appears, therefore, that the clinical features may enable severe cases to be diagnosed correctly in life. Nevertheless, it is doubtful whether the clinical features are always sufficiently clear-cut to distinguish less severe hydranencephaly from other forms of hydrocephalus. Hydranencephalic patients living long enough to be classed as mentally defective, as our Case 1, could be expected to present even more frequently with atypical features.

\section{Summary}

Hydranencephaly is a congenital condition in which the cerebral hemispheres are replaced by thin sacs containing cerebrospinal fluid. Characteristic- ally, the sac wall consists of pia and arachnoid overlying the glial layer-all that remains of the cerebral cortex and white matter.

Hydranencephaly is a descriptive term not implying, on the evidence available, specific aetiology, pathogenesis or clinical features which would always distinguish it from other severe variants of hydrocephalus or porencephaly. It is unfortunate that, etymologically, the term suggests a combination of hydrocephalus and anencephaly, since it is in fact unrelated to anencephaly, hence 'hydrencephaly' is more appropriate.

These conclusions are reached by a review of the literature and the study of a fairly typical case of hydranencephaly in a $4 \frac{1}{2}$-year-old epileptic idiot and of two hydrocephalic cases presenting partial features of hydranencephaly.

Toxoplasmosis was suggested by the findings in the first case but this could not be verified.

We are indebted to our colleagues at the Fountain Hospital for access to their case records and their helpful criticism. REFERENCES

Becker, H. (1949). Dtsch. Z. Nervenheilk., 161, 407, 446.

Beswick, W. F. (1948). N.Y. St. J. Med., 48, 2364.

Bókay, J. von (1923). Mschr. Kinderheilk., 25, 43

Crome, L. (1956). J. Path. Bact., 71, 335.

Cruveilhier, J. (1829). Anatomie pathologique du corps humain, p. 1. Paris.

1862). Traité d'anatomie pathologique générale, Vol. 4, p. 75.

Globus, J. H. (1921). Arch. Neurol. Psychiat. (Chicago), 6, 652.

Hallervorden, J. and Meyer, J. E. (1956). In Handbuch der speziellen pathologischen Anatomie und Histologie, p. 222, edited by
O. Lubarsch, F. Henke and R. Rössle, Berlin, Band 13. Teil 4.

Hamby, W. B., Krauss, R. F. and Beswick, W. F. (1950). Pediatrics, 6, 371 .

Hurowitz, J. (1936). Schweiz. Arch. Neurol. Psychiat., 38, 207.

Kluge, H. (1902). Z. Kinderheilk., 23, 208.

Kobelt, W. (1938). Thesis, Univ. Heidelberg

Kopp, J. (1912). Dtsch. Z. Chir., 116, 226.

Lange-Cosack, H. (1944). Arch. Psychiat. Nervenkr., 117, 595.

Meyer, J. E. (1949). Z. Kinderheilk., 67, 123.

Moser, E. (1952). Ann. paediat. (Basel), 179, 193.

Najman, E. (1953). Ibid., 181, 249.

Olive, J. T. and DuShane, J. W. (1953). Amer. J. Dis. Child., 85, 43.

Olive, J. T. and DuShane, J. W. (1953). Amer. J. Dis. Child., 85, 43.
Peters, G. (1951). Spezielle Pathologie der Krankheiten des zentralen und peripheren Nervensystems, p. 194. Stuttgart.

Russell, D. S (1949). Observations on the Pathology of Hydrocephalus, Spec. Rep. Ser. med. Res. Coun. (Lond.). No. 265.

Sabin, A. B. and Feldman, H. A. (1949). J. Pediat., 35, 296.

Schwartz, P. (1927). Ergebn. inn. Med. Kinderheilk., 31, 165.

Spielmeyer, W. (1905). Arch. Psychiat. Nervenkr., 39, 807.

Spielmeyer, W. (1905). Arch. Psychiat. Nervenkr.

Strasburger (1910). Dtsch. med. Wschr., 36,
Sutton, D. (1950). Brit. J. Radiol., 23, 208.

Thelander, H. E., Shaw, E. B. and Piel, J. J. (1953). J. Pediat., 42, 680 .

Watson, E. H. (1944). Amer. J. Dis. Child., 67, 282.

Whittem, J. H. (1957). J. Path. Bact., 73, 375. 